\title{
Peptide Aptamer-Based ELISA-Like System for Detection of Cathepsin E in Tissues and Plasma
}

\begin{abstract}
Koichiro Kitamura ${ }^{1,2,3}$, Madhu Biyani ${ }^{2,3}$, Masae Futakami ${ }^{2,3}$, Sachika Ueno-Tsuji ${ }^{2}$, Miho Suzuki ${ }^{2}$, Tomoyo Kawakubo ${ }^{3,4}$, Kenji Yamamoto ${ }^{3,4}$ and Koichi Nishigaki $^{2,3 *}$
${ }^{1}$ Janusys Corporation, \#508, Saitama Industrial Technology Center, 3-12-18 Kami-Aoki, Kawaguchi, Saitama 333-0844, Japan

${ }^{2}$ Department of Functional Materials Science, Graduate School of Science and Engineering, Saitama University, 255 Shimo-okubo, Saitama 338-8570, Japan

${ }^{3}$ City Area Program Saitama Metropolitan Area, Saitama small and medium Enterprises Development Corporation, 2-3-2 Kamiochiai, Chuo-ku, Saitama City, Saitama 338-0001, Japan

${ }^{4}$ Proteolysis Research Laboratory, Graduate School of Pharmaceutical Sciences, Kyushu University, Higashi-ku, Fukuoka 812-8582, Japan

Abstract

ELISA (enzyme-linked immunosorbent assay), a highly sensitive and powerful molecular detection tool, has been constructed based on antibodies, as its name denotes. However, it is not so easy to prepare antibodies for any target molecule and there are still problems in their cost and stability. In this study, peptide-based ELISA-like systems (pepELISA) were first constructed and shown to be effective. In particular, if the target is an enzyme, such as cathepsin $\mathrm{E}$, that can generate a fluorescent product, the construct of pep-ELISA can be very simple, as its name indicates; i.e., Enzyme-on-Peptide. These constructs, together with peptide-based Sandwich ELISA-like (Sandwich pep-ELISA), were actually constructed and examined using the tissues and blood specimens extracted from cathepsin E-normal/knockout rats. Through these experiments, the sufficient sensitivity $(\sim 10 \mu \mathrm{g} / \mathrm{ml})$ and methodological convenience of pep-ELISA were demonstrated.
\end{abstract}

Keyword: Peptide aptamer; ELISA-like; Cathepsin E; Diagnosis; Protease

Abbreviations: CatE: Cathepsin E; ELISA: Enzyme-Linked Immunosorbent Assay; pep-ELISA: Peptide Aptamer-Based ELISALike Assay; Sandwich pep-ELISA: Peptide-Aptamer-Based Sandwich ELISA-Like Assay; EOP: Enzyme on Peptide

\section{Introduction}

Highly sensitive detection methods of molecules are essential for scientific and medical purposes: information molecules, such as cytokines and hormones, and possible biomarkers, such as PSA and GAT, are usually in very low concentrations of less than $\mu \mathrm{M}$ and even far less (sub pM or so) [1,2].

Therefore, special techniques like RIA (radio-immunoassay), ELISA (enzyme linked immunosorbent assay) and others have been developed for this purpose [3-6]. Among these, ELISA is the most popular and widely applicable $[7,8]$ because it depends on antibodies and enzymes but not on radio-isotopes, thus being easily manipulated in usual laboratories. Currently, the most sophisticated method for the high sensitivity must be the ELISA system where the antibody plays the pivotal role. Since the diversities of antibodies have been developed and are still expanding $[9,10]$, ELISA has become nearly de-facto standard for high sensitivity detection of molecules.

In this paper we demonstrate that peptides can play the role of antibodies in the ELISA system in some cases. This is beneficial since it is difficult to identify desirable antibodies (of high affinity and stability) and costly to prepare antibodies in a large quantity while peptides have been becoming more easily developed by the emerging in vitro evolution method [11-13] than antibodies. At this moment, we have to recall major materials for in vitro evolution, i.e., RNA/DNA aptamers, which have been used for developing various functional molecules such as biosensors [14,15], biomarkers [16], diagnostics [17,18], and therapeutics like Macugen [19-21] and are now increasingly developing owing to its readiness in the molecular evolution [22,23]. Since they have potentially a strong binding affinity to the target molecule at even a pM level of the dissociation constant [24], the RNA/DNA aptamers must be surely choices for developing the substitute for the antibody working for ELISA. However, so far as we know, RNA/DNA aptamersubstituted Sandwich ELISA, a highly specific and useful type of ELISA, has been reportedonce [25] or so probably due to their bulky molecular size (20-30 kD or more) and the conformationally strict requirement [26]. Herein, peptides have appeared as a promising substitute for antibodies. Originally, the peptide has the favorable property that it is far smaller than an antibody ( $\sim 100$ fold) and thus is easy to be synthesized and modified and is less costly. Therefore, it is quite natural to seek away to replace antibodies with peptides in order to set up an ELISA-like system.

In this paper, we report two types of peptide-based ELISA-like systems. One is enzyme-on-peptide $(E O P)$, which is much simpler as it consists of a peptide and a target enzyme only. The other looks like the conventional sandwich ELISA where antibodies are replaced with peptides. These were confirmed to be effective using protease cathepsin $\mathrm{E}$ as the target.

\section{Materials and Methods}

\section{Peptides preparation}

The peptides used were cathepsin E (hereafter, CatE) inhibiting/ activating peptides that were identified by the in vitro evolution method (Table 1) [11].The activities of peptides (pp2 and pp1015 obtained at

${ }^{*}$ Corresponding author: Koichi Nishigaki, Department of Functional Materials Science, Graduate School of Science and Engineering, Saitama University, 255 Shimo-okubo, Saitama 338-8570, Japan, Tel: +81-48-858-3533; E-mail: koichi@ $\underline{\text { fms.saitama-u.ac.jp }}$

Received December 25, 2010; Accepted February 17, 2011; Published February 19, 2011

Citation: Kitamura K, Biyani M, Futakami M, Ueno-Tsuji S, Suzuki M, et al. (2011) Peptide Aptamer-Based ELISA-Like System for Detection of Cathepsin E in Tissues and Plasma. J Mol Biomark Diagn 2:104. doi:10.4172/2155-9929.1000104

Copyright: (c) 2011 Kitamura K, et al. This is an open-access article distributed under the terms of the Creative Commons Attribution License, which permits unrestricted use, distribution, and reproduction in any medium, provided the original author and source are credited. 
Citation: Kitamura K, Biyani M, Futakami M, Ueno-Tsuji S, Suzuki M, et al. (2011) Peptide Aptamer-Based ELISA-Like System for Detection of Cathepsin E in Tissues and Plasma. J Mol Biomark Diagn 2:104. doi:10.4172/2155-9929.1000104

Page 2 of 4

\begin{tabular}{|c|c|c|c|c|}
\hline \multirow{2}{*}{ Name } & \multirow{2}{*}{ Amino acid sequence $(\mathrm{N} \rightarrow \mathrm{C})$} & \multirow{2}{*}{$\begin{array}{l}\text { Size } \\
\text { (a.a.) }\end{array}$} & \multicolumn{2}{|c|}{ Activity (\%) } \\
\hline & & & $A_{\mathrm{dp}}^{\mathrm{a}}$ & $A_{\mathrm{sy}}^{\mathrm{b}}$ \\
\hline pp 2 & NYKDSCIGGD LTPSSCGGII IISCIA & 26 & 68.9 & 59.5 \\
\hline $\begin{array}{l}\mathrm{pp} \\
1015\end{array}$ & $\begin{array}{l}\text { PGSSSCIIGG GPGGDGGDPG GPTDSIIIIS } \\
\text { RIG }\end{array}$ & 33 & 162.7 & 160.7 \\
\hline $\begin{array}{l}\text { pa } \\
4043\end{array}$ & PGIKPPPCII IIG & 13 & $160 \pm 20^{c}$ & - \\
\hline
\end{tabular}

${ }^{\mathrm{a}} A_{\mathrm{dp}}$ is the activity of an in vitro translation synthesized peptide

${ }^{\mathrm{b}} A_{\mathrm{sy}}$ is the activity of a chemically synthesized peptide

'Under neutral $\mathrm{pH}$ conditions

Table 1: Characteristics of peptides used for the pep-ELISA system.

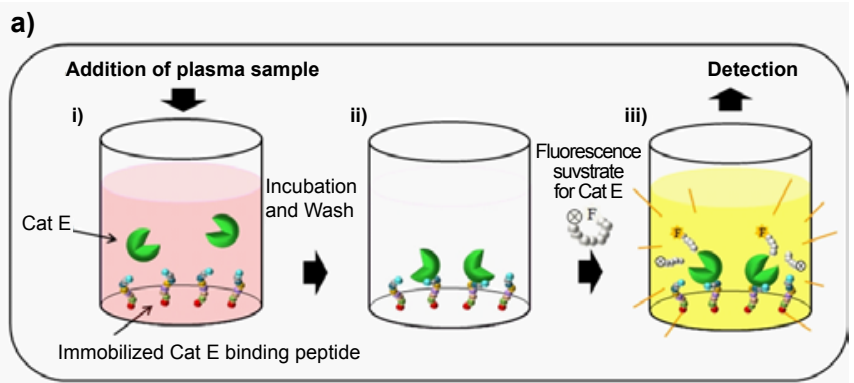

b)

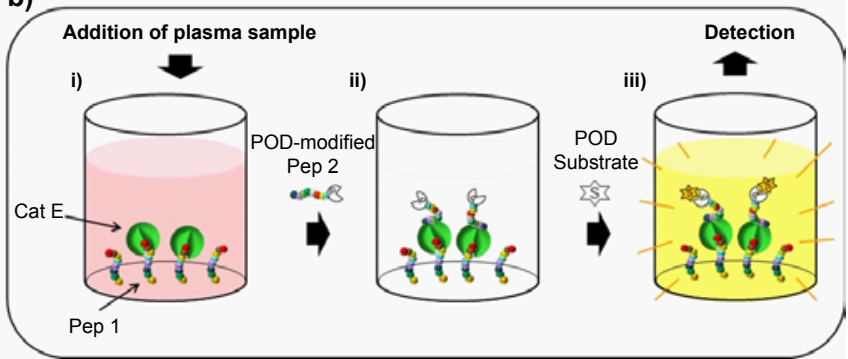

Figure 1: Schematic drawing of peptide-based ELISA-like assay (pepELISA). a) Enzyme-on-peptide (EOP) mode. The target protein (enzyme cathepsin E), trapped by the peptide on the matrix (or a bead), exerts the protease activity, generating fluorescent products. b) Peptide-based Sandwich ELISA-like. The roles of two kinds of antibodies are replaced by two kinds of peptides. The other scheme is quite similar tothe conventional one.

acidic $\mathrm{pH}(\mathrm{pH} 4.5))$ were analyzed according to previously reported CatE activity assay with an in vitro synthesis-derived peptide and, for further confirmation, with a chemically synthesized peptide [11]. The activity of the peptide p4043, which was obtained as a CatEactivator at neutral $\mathrm{pH}(\mathrm{pH} 7.4)$,was measured in slightly modified assay conditions using a novel substrate(Nma-Gly-Gly-Arg-Arg-SerGly-Thy-Cys-Gly(Dnp)-D-Arg-NH2)thatcan work at a neutral $\mathrm{pH}$ for CatE. In general, CatE was pre-incubated with a peptide aptamer (either inhibitor or activator) in an equal molar ratio at $25^{\circ} \mathrm{C}$ for $10 \mathrm{~min}$ and was combined with a fluorogenic substrate to monitor the enzymatic activity. The CatE-activity (activation/inhibition) was measured by subtracting the background fluorescence of the negative reaction mixture consisting of only the fluoregenic substrate $\left(B_{f}\right)$ from that of the reaction product $\left(C_{f}\right.$ forthe control reaction without regulatory peptides or $S_{f}$ for the sample reaction with regulatory ones). The percentage of inhibition $(I)$ or activation $(A)$ was calculated by fitting the data to the following equations.

$$
\begin{array}{ll}
I=100 \times\left\{1-\left(S_{f}-\mathrm{B}_{f}\right) /\left(C_{f}-\mathrm{B}_{f}\right)\right\} & \text { \% inhibition } \\
A=100 \times\left(S_{f}-\mathrm{B}_{f}\right) /\left(C_{f}-\mathrm{B}_{f}\right) & \% \text { activation }
\end{array}
$$

These peptides were chemically synthesized by Nihon Bio Service (Scrum Corporation, Japan) and were confirmed by MALDI-TOF-MS.

\section{Peptide immobilization for the Enzyme-on-Peptide (EOP)- typed pep-ELISA}

Peptide molecules were diluted with a Coupling buffer $(0.2 \mathrm{M}$ $\mathrm{NaHCO}_{3}, 0.5 \mathrm{M} \mathrm{NaCl},(\mathrm{pH} 8.3)$ ) to $1 \mathrm{mg} / \mathrm{ml}$, and each of $50 \mu \mathrm{l}$ of the peptide solution was poured into an array of a Peptide coating plate (TaKaRa, Japan). Immediately, $10 \mu$ l of Reaction solution (TaKaRa) was added into each well and incubated at room temperature for $2 \mathrm{~h}$. After incubation, the solutions were moved from the wells of the plate and the peptide-coated wells were washed with $200 \mu$ of distilled water three times. Then, $200 \mu \mathrm{l}$ of a Blocking solution $(0.5 \mathrm{M}$ ethanolamine, $0.5 \mathrm{M} \mathrm{NaCl}(\mathrm{pH} 8.3)$ ) was added into each well and they were incubated at room temperature for $1 \mathrm{~h}$ in order to deprive them of non-specific binders. After removing the Blocking solution, the wells were washed with $200 \mu \mathrm{l}$ of distilled water three times.

\section{Trapping the target enzyme by the cognitive peptide (EOP)}

First, CatE protease-containing tissue extracts or serum were $\mathrm{pH}$-adjusted with a buffer $(500 \mathrm{mM}$ sodium acetate, $1 \mathrm{M} \mathrm{NaCl}, \mathrm{pH}$ 4.0) to $\mathrm{pH} 4.5$. When the precipitation was generated, it was removed by centrifugation at $15,000 \mathrm{rpm}$ for $5 \mathrm{~min}$ and the supernatant was recovered. The supernatant of $30 \mu$ lwasaddedinto each of the cognitive peptide-immobilized wells and they were incubated at room temperature for $20 \mathrm{~min}$ and removed of the solution. That remaining in each well on the plate was washed with $200 \mu \mathrm{l}$ of distilled water twice.

\section{Measurement in EOP}

The amount of CatE trapped on the peptide was directly assayed with the fluorogenic substrate MOCAc-Gly-Ser-Pro-Ala-Phe-Leu-AlaLys(Dnp)-D-Arg-NH2(KYS-1) as previously described [27]. Briefly, $5 \mu \mathrm{l}$ of $100 \mu \mathrm{M}$ substrate and $45 \mu \mathrm{l}$ of $50 \mathrm{mM}$ sodium acetate, $100 \mathrm{mM}$ $\mathrm{NaCl}, \mathrm{pH} 4.5$, were added to each well and then incubated at $40^{\circ} \mathrm{C}$ for $10 \mathrm{~min}$. The increase in fluorescence intensity produced by substrate cleavage during incubation was measured at an emission wavelength at $430 \mathrm{~nm}$ with excitation at $360 \mathrm{~nm}$ using a fluorescence plate reader FluPOLO (TaKaRa, Japan).

\section{Peptide-based sandwich ELISA-like assay (Sandwich pep- ELISA)}

The other type of peptide apatamer-based assay, CatE trapped onto the microtiter plates by the first cognitive peptide were sandwiched by adding $50 \mu \mathrm{l}$ of the peroxidase-labeled second cognitive peptide aptamer $(0.5 \mathrm{ng} / \mu \mathrm{l})$. After incubation at room temperature for $20 \mathrm{~min}$, each well was washed three times with $200 \mu \mathrm{l}$ of distilled water. Then, $100 \mu \mathrm{l}$ of the peroxidase substrate (Quanta Blu Fluorogenic Peroxidase Substrate (TaKaRa, Japan)) was added to each well and incubated at $37^{\circ} \mathrm{C}$ for 10 $\mathrm{min}$. The fluorescence intensity was measured as described above.

\section{Results and Discussion}

A novel technology to identify protease-inhibitory or activating peptides has been developed recently [11]. Owing to this technology, we can easily obtain such peptide aptamers as strongly binding to proteases instead of antibodies. Since peptides can be chemically synthesized in a large quantity, they are apromising substitution for antibodies in various purposes (Immunostaining, Western blotting, Immunoprecipitation and others), especially in ELISA technology.

Analogously to the antibody technology, we can think of two modes of pep-ELISA: 'Ensyme-on-peptide (EOP)'andpeptide-based Sandwich ELISA-like (Figure 1). Evidently, the former is effective when the binding site of a peptide is apart from its catalytic site and 


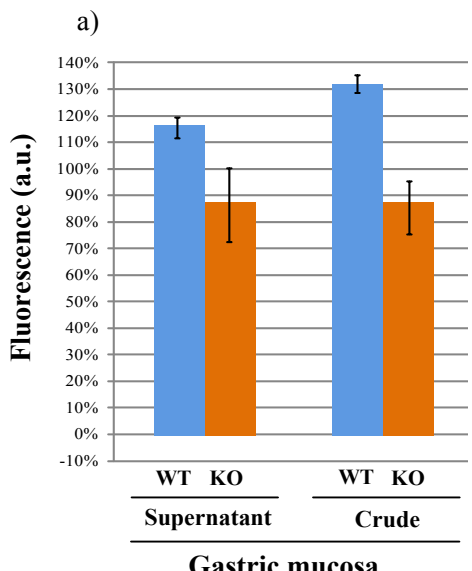

b)

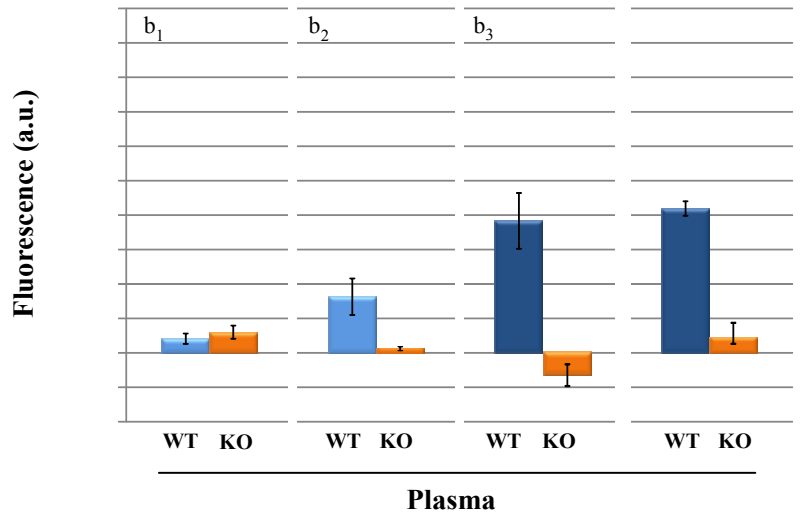

Figure 2: Applications of EOP (enzyme-on-peptide)-mode pep-ELISA. In this experiment, the fluorescence intensity can be regarded to be proportional to the amount of the enzyme CatE since it generates the fluorescent substrate by cleaving the fluorogenic substrate. a) Measurement of CatE levels of different specimens (rat spleen and gastric mucosa extracted from cathepsin E-gene knockout and wild rats). Since the peptide used (pp2) has a binding (and inhibitory) activity at $\mathrm{pH} 4.5$, these specimens in physiological conditions (at a neutral $\mathrm{pH}$ ) were pre-treated to adjust the $\mathrm{pH}$ to $\mathrm{pH}$ 4.5. The aggregates generated in this process were removed (supernatant) or not removed (crude) during the enzyme activity assay. b) The effect of the change in the peptide aptamer composing EOP on the CatE-binding. The peptides used are (b1) non-CatE-binding octapeptide (the sequence of PCSELINT), (b2) pp2 (CatEinhibitor at pH4.5), and (b3) pp1015 (CatE-activator at pH4.5). The specimens used were plasma extracted from wild type (WT) and knockout (KO) rats. c) CatE measurement by the EOP-mode pep-ELISA made of a peptide aptamer (pa4043) selected at a neutral $\mathrm{pH}(\mathrm{pH7}$.4). In this case, the trapping of CatE was performed at a neutral $\mathrm{pH}$, where the peptide pa4043is active, while the enzyme activity was monitored at $\mathrm{pH} 4.5$ using the supernatant of centrifugationtreated plasma solution(the same origin as in b)which had been subjected topH-alteration from a physiological $\mathrm{pH}$ to $\mathrm{pH} 4.5$ (see Materials and Methods) Note that CatE does not need to be bound to the peptide when its activity is monitored at $\mathrm{pH} 4.5$ (where the peptide selected at $\mathrm{pH} 7.4$ will probably lose its binding affinity to CatE). Throughout the above experiments, the CatE activity at $\mathrm{pH} 4.5$ was compared, making the comparison of activity easy. Statistics were taken from three independent experiments except b1 $(n=2)$.

the binding of the peptide does not severely impinge on the catalytic activity, which is usually the case with weak inhibitory peptides and activity-enhancing peptides. This type of the peptide aptamer-based ELISA-like assay (briefly, pep-ELISA) was constructed using i) a weak inhibitory peptide (pp2 in Table 1) and ii) activating peptides (pp1015 and pa 4043 in Table 1).

Cathepsin E specimens from different tissues (gastric mucosa and spleen) were tested with/without removing the aggregates generated by the $\mathrm{pH}$ alteration from the neutral to the acidic ( $\mathrm{pH} 4.5)$. As can be seen in Figure 2a, CatE from both sources can be measured with a difference between the wild (WT) and the knock-out (KO), although the values for the gastric mucosa of the knock-out rats were significantly higher, probably reflecting the abundant existence of family proteases such as cathepsin D in the tissue. Nevertheless, there was a reasonable difference in CatE activity between the wild and the knock-out specimens (Figure 2a). Evidently, there is only a minor difference between with and without removal of the aggregates, indicating the intactness of CatE and the negligible effect of co-precipitation. Since the level of CatE in the wild rat plasma can be estimated to be $\sim 10 \mu \mathrm{g} / \mathrm{ml}$ (Supplementary Figure 1), this result shows the sufficient sensitivity of pep-ELISA, and is also supported by the fact that this peptide (pp2) hasa sufficiently strong dissociation constant of $570 \mathrm{pM}$ by the surface plasma resonance (SPR) method using a Biacore 2000 (GE Healthcare, UK) in the mode of making a peptide as the ligand and the CatE molecule as the analyte (Table 1).

For the sake of methodological convenience, a CatE-activating peptide in the neutral $\mathrm{pH}$ (pa 4043) was selected and used for the same pep-ELISA purpose. As can be seen in Figure 2c, this case could also work, meaning the possibility of the direct measurement of blood samples without $\mathrm{pH}$ adjustment. The EOP result obtained with the neutral $\mathrm{pH}$ CatE-activating peptide seems to be supportive of an idea that protease-activating peptides may provide higher sensitivities than inhibitory ones (Figure 2b1\& b2) since both peptides, inhibitory and activating, have a comparable $\mathrm{Kd}$ (to be published elsewhere).

The peptide-based Sandwich ELISA-like assay (Sandwich pep-ELISA) was also tested and shown to be effective (Figure 3, Supplementary Figure 2). So far as we know, this is the first case in which peptides have been shown to be used as substitutes of antibodies. Since the identification of a specific peptide aptamer against a target is very easy in contrast to finding an antibody, we believe the introduced method as a strong impact on the fields of biomolecular sensing and imaging applied to science and medicine.

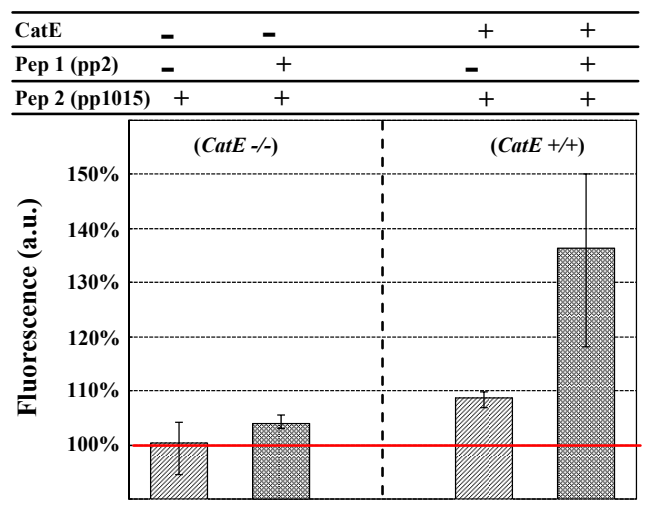

Figure 3: Peptide-based Sandwich ELISA-like assay (Sandwich pepELISA). In this experiment, the complete sandwich construct (pp2 + CatE + pp1015) and incomplete sandwich construct (CatE + pp1015 without pp2) were tested against the wild and the CatE-gene knockout rat plasma samples. The primary peptidepep 1 (pp2) was immobilized on to the surface of the microplate and then CatE was bound to pep 1 or not. Next, the secondary peptide pep 2 ( $p$ 1015) combined with an enzyme horse-radish peroxidase was added, bound to CatE, and then washed to remove the unfixed peroxidase. Note that in this case, CatE works as only a bridge between two peptides and does not work as an enzyme. Statistics were taken from 3 trials. 
Citation: Kitamura K, Biyani M, Futakami M, Ueno-Tsuji S, Suzuki M, et al. (2011) Peptide Aptamer-Based ELISA-Like System for Detection of Cathepsin E in Tissues and Plasma. J Mol Biomark Diagn 2:104. doi:10.4172/2155-9929.1000104

Page 4 of 4

Inconclusion, CatE-peptide-aptamers could be used for substitutes of antibodies in constructing a peptide-based ELISA-like assay (pepELISA) for the detection of CatE in tissues and plasma. The modes of pep-ELISA, EOP (enzyme-on-peptide) and Sandwich pep-ELISA, were all shown to be effective.

\section{Acknowledgements}

This study was supported by a grant from Ministry of Education, Culture Sports, Science, and Technology of Japan (MEXT) donated to the City Area Collaboration Promoting Project (Saitama Prefecture Central Area).

\section{References}

1. Udagawa Y,Aoki D, Ito K, Uejima T, Uemura M, etal. (1998)Clinical characteristics of a newly developed ovarian tumour marker, galactosyltransferase associated with tumour (GAT). Eur J Cancer 34: 489-495.

2. Brawer MK (1999) Prostate-Specific Antigen: Current Status. Cancer J Clin 49 264-281.

3. Voller A, Bartlett A, Bidwell DE (1978) Enzyme immunoassays with specia reference to ELISA techniques. J Clin Pathol 31: 507-520.

4. Goldberg ME, Djavadi-Ohaniance L (1993) Methods for measurement of antibody/antigen affinity based on ELISA and RIA. Curr Opin Immunol 5: 278281.

5. Gniewek RA, Stites DP, McHugh TM, Hilton JF, Nakagawa M (1997) Comparison of antinuclear antibody testing methods: immunofluorescence assay versus enzyme immunoassay. Clin Diagn Lab Immunol 4: 185-188.

6. Safi MA (2010) An overview of various labeled assays used in medical laboratory diagnosis. Immune and non-immune assays. Saudi Med J 31: 359368

7. Tritten L, Matile H, Brun R, Wittlin S (2009) A new double-antibody sandwich ELISA targeting Plasmodium falciparum aldolase to evaluate anti-malarial drug sensitivity. Malar J 12: 226.

8. Kimura R, Yoda A, Hayashizaki Y, Chiba J (2010) Novel ELISA using intracellularly biotinylated antigen for detection of antibody following DNA immunization. Jpn J Infect Dis 63: 41-48.

9. Seo H, Masuoka M, Murofushi H, Takeda S, Shibata T, et al. (2005) Rapid generation of specific antibodies by enhanced homologous recombination. Nat Biotechnol 23: 731-735.

10. Isaacs JD (2009) Antibody engineering to develop new antirheumatic therapies. Arthritis Res Ther 11: 225

11. Kitamura K, Yoshida C, Kinoshita Y, Kadowaki T, Takahashi Y, et al. (2009) Development of systemic in vitro evolution and its application to generation of peptide-aptamer-based inhibitors of cathepsin E. J Mol Biol 17: 1186-1198.
12. Heinis C, Rutherford T, Freund S, Winter G (2009) Phage-encoded combinatorial chemical libraries based on bicyclic peptides. Nat Chem Biol 5: 502-507

13. Wada A, Ito $Y$ (2009) The highly stabilized ribosome display selection of metalbinding peptide aptamers. Nucleic Acids Symp Ser 53: 263-264.

14. Sefah K, Phillips JA, Xiong X, Meng L, Van Simaeys D, et al (2009) Nucleic acid aptamers for biosensors and bio-analytical applications. Analyst 134 1765-1775.

15. Juskowiak B (2010) Nucleic acid-based fluorescent probes and their analytical potential. Anal Bioanal Chem Epub Oct 29.

16. Dua P, Kim S, Lee DK (2008) Patents on SELEX and therapeutic aptamers Recent Pat DNA Gene Seq 2: 172-186.

17. Tombelli S, Minunni M, Mascini M (2005) Analytical applications of aptamers. Biosens Bioelectron 20: 2424-2434.

18. de Franciscis V, Esposito CL, Catuogno S, Cellai L, Cerchia L (2009) Aptamers as innovative diagnostic and therapeutic agents in the central nervous system. CNS Neurol Disord Drug Targets 8: 393-401.

19. Fichou Y, Férec C (2006) The potential of oligonucleotides for therapeutic applications. Trends Biotechnol 24: 563-570.

20. Trujillo CA, Nery AA, Alves JM, Martins AH, Ulrich H (2007) Development of the anti-VEGF aptamer to a therapeutic agent for clinical ophthalmology. Clin Ophthalmol 1: 393-402.

21. Barbas AS, Mi J, Clary BM, White RR (2010) Aptamer applications for targeted cancer therapy. Future Oncol 6: 1117-1126.

22. Guthrie JW, Hamula CL, Zhang H, Le XC (2006) Assays for cytokines using aptamers. Methods 38: 324-330.

23. Kulbachinskiy AV (2007) Methods for selection of aptamers to protein targets Biochemistry (Moscow) 72: 1505-1518.

24. Zhao S, Yang W, Lai RY (2011) A folding-based electrochemical aptasensor for detection of vascular endothelial growth factor in human whole blood. Biosens Bioelectron 15: 2442-2447.

25. Tennico YH, Hutanu D, Koesdjojo MT, Bartel CM, Remcho VT (2010) On-chip aptamer-based sandwich assay for thrombin detection employing magnetic beads and quantum dots. Anal Chem 82: 5591-5597.

26. Baldrich E, Restrepo A, O'Sullivan CK (2004) Aptasensor development: elucidation of critical parameters for optimal aptamer performance. Anal Chem 76: 7053-7063.

27. Yasuda Y, Kohmura K, Kadowaki T, Tsukuba T, Yamamoto K (2005) A new selective substrate for cathepsin $E$ based on the cleavage site sequence of a2-macroglobulin. Biol Chem 386: 299-305. 